\title{
Phase 1 trial of the oral AKT inhibitor MK-2206 plus carboplatin/paclitaxel, docetaxel, or erlotinib in patients with advanced solid tumors
}

L Rhoda Molife ${ }^{1 *}$, Li Yan², Joanna Vitfell-Rasmussen ${ }^{1}$, Adriane M Zernhelt ${ }^{2}$, Daniel M Sullivan ${ }^{3}$, Philippe A Cassier ${ }^{1,7}$, Eric Chen ${ }^{4}$, Andrea Biondo ${ }^{1}$, Ernestina Tetteh², Lillian L Siư ${ }^{4}$ Amita Patnaik ${ }^{5}$, Kyriakos P Papadopoulos ${ }^{5}$,

Johann S de Bono ${ }^{1,6}$, Anthony W Tolcher ${ }^{5}$ and Susan Minton ${ }^{3}$

\begin{abstract}
Background: Inhibition of AKT with MK-2206 has demonstrated synergism with anticancer agents. This phase 1 study assessed the MTD, DLTs, PK, and efficacy of MK-2206 in combination with cytotoxic and targeted therapies.

Methods: Advanced solid tumor patients received oral MK-2206 45 or 60 mg (QOD) with either carboplatin (AUC 6.0) and paclitaxel $200 \mathrm{mg} / \mathrm{m}^{2}$ (arm 1), docetaxel $75 \mathrm{mg} / \mathrm{m}^{2}$ (arm 2), or erlotinib 100 or $150 \mathrm{mg}$ daily (arm 3); alternative schedules of MK-2206 135-200 mg QW or 90-250 mg Q3W were also tested.

Results: MTD of MK-2206 ( $\mathrm{N}=72$ ) was $45 \mathrm{mg}$ QOD or $200 \mathrm{mg}$ Q3W (arm 1); MAD was $200 \mathrm{mg}$ Q3W (arm 2) and $135 \mathrm{mg} \mathrm{QW}$ (arm 3). DLTs included skin rash (arms 1, 3), febrile neutropenia (QOD, arms 1, 2), tinnitus (Q3W, arm 2), and stomatitis (QOD, arm 3). Common drug-related toxicities included fatigue (68\%), nausea (49\%), and rash (47\%). Two patients with squamous cell carcinoma of the head and neck (arm 1; Q3W) demonstrated a complete and partial response (PR); additional PRs were observed in patients (1 each) with melanoma, endometrial, neuroendocrine prostate, NSCLC, and cervical cancers. Six patients had stable disease $\geq 6$ months.
\end{abstract}

Conclusion: MK-2206 plus carboplatin and paclitaxel, docetaxel, or erlotinib was well-tolerated, with early evidence of antitumor activity.

Trial registration: ClinicalTrials.gov: NCT00848718.

Keywords: MK-2206, AKT inhibitor, Protein serine-threonine kinase, Phase 1, Chemotherapy, Combination therapy, Solid tumors

\section{Introduction}

The phosphatidylinositide 3-kinase (PI3K)/AKT/mammalian target of rapamycin (mTOR) signaling pathway is a critical driver of tumor progression [1]. Hyperactivation of this pathway is an important driver of malignant progression via increased cancer cell growth, survival, and metabolism, as well as chemoresistance [2,3]. Hyperactivation may occur through different mechanisms, including upstream stimulation by receptor tyrosine kinases, PIK3CA and AKT mutations or amplifications, and loss of PTEN function [4]. In view of the key role of the PI3K/

\footnotetext{
* Correspondence: rhoda.molife@icr.ac.uk

${ }^{1}$ Drug Development Unit, The Institute of Cancer Research/The Royal Marsden NHS Foundation Trust, Downs Road, Sutton, Surrey SM2 5PT, UK
} Full list of author information is available at the end of the article
AKT/mTOR pathway in cancer, multiple strategies have been developed in recent years to target critical components of this signaling cascade [5-7]. AKT (protein kinase $\mathrm{B}[\mathrm{PKB}])$, a serine/threonine kinase, is directly activated in response to PI3K and is a major effector of PI3K in cancers [8-10]. There are 3 different protein isoforms, AKT1, AKT2, and AKT3, with overlapping and distinct roles in cancer; for example, AKT1 promotes cellular survival and growth [11]. In addition, AKT activation and overexpression are commonly associated with chemo- and radioresistance [2,12], and dominant-negative mutants of AKT have been shown to enhance the activity of chemotherapeutics $[13,14]$.

Adenosine triphosphate (ATP) competitive and allosteric classes of small-molecule AKT inhibitors with 
varying potencies and specificities for the different AKT isoforms have been developed [5,7]. One member of the allosteric class is MK-2206 (Merck \& Co., Inc., Whitehouse Station, NJ, USA), an oral, highly selective inhibitor of AKT that binds at a site in the pleckstrin-homology (PH) domain, distinct from the ATP-binding pocket, resulting in a conformational change that prevents the localization of AKT to the plasma membrane and its subsequent activation $[15,16]$. It displays nanomolar $(\mathrm{nM})$ potency against all 3 AKT isoforms (AKT1, half maximal inhibitory concentration $[\mathrm{IC} 50]=5 \mathrm{nM}$; AKT2, IC50 = $12 \mathrm{nM}$; AKT3, IC50 $=65 \mathrm{nM}$ ) [16]. A first-in-human phase 1 combination study defined the maximum tolerated dose (MTD), pharmacokinetics (PK), and pharmacodynamics (PD) of an alternate day (QOD) and weekly (QW) schedule of MK-2206 in patients with advanced solid tumors $[17,18]$. The dose-limiting toxicities (DLT) were rash and stomatitis. The PK profile was dose proportional, and PD analysis of both schedules demonstrated the downstream effects of AKT inhibition with a significant decline in phosphorylated AKT (pAKT; ser473) in post-treatment tumor biopsies, and in pPRAS40 (rhr246) in hair follicles. Reversible hyperglycemia and an increase in insulin c-peptide further confirmed target modulation. Minor responses were demonstrated in 2 patients with neuroendocrine pancreatic cancers and 1 patient with pancreatic adenocarcinoma and PTEN loss (in addition to KRAS G12D mutation).

In preclinical models, MK-2206 enhanced the activity of conventional cytotoxics and other molecularly targeted therapies [19]. In vitro, MK-2206 demonstrated synergy with both erlotinib and lapatinib in inhibiting proliferation and inducing apoptosis of non-small cell lung (NSCLC) cell lines, including those that were RAS mutant, and breast cancer cell lines. Although treatment with erlotinib inhibited EGFR and pERK phosphorylation of the RAFRAS-MEK pathway in the A431 cell line and mouse NCIH292 tumor xenografts, there was no effect on pAKT and pRAS40, downstream markers of AKT inhibition. However, the combination with MK-2206 resulted in decreased levels of pAKT and pRAS40. The inhibition of both pathways led to more profound inhibition of pGSK3b and pS6, which are downstream signaling proteins that correlate with cell growth and survival. The combination also demonstrated significantly greater in vivo tumor growth suppression and tumor regressions over each single agent using both a 3 times per week and QW schedule of MK-2206 in the mouse tumor xenografts.

In vitro, MK-2206 demonstrated synergy with several conventional cytotoxics, including carboplatin and docetaxel, in inhibiting the growth of NCI-H292 and A2780 tumor cells [19]. Carboplatin-induced apoptosis was also enhanced by MK-2206 in a sequence-dependent manner: concurrent treatment or pretreatment with carboplatin induced A2780 cell death in a dose-dependent manner, whereas pretreatment with MK-2206 did not. In vivo, MK-2206 synergised with docetaxel, carboplatin, and gemcitabine in inhibiting the growth of PC-3 prostate and NCI-H462 tumor xenografts with a similar-sequence dependent pattern as for carboplatin in vitro.

On this background, a multi-arm phase 1 dose-escalation study of MK-2206 in combination with carboplatin and paclitaxel, docetaxel, or erlotinib in patients with advanced solid tumors was initiated. The primary objectives were to evaluate safety and tolerability, DLTs, and the MTD/recommended phase 2 dose (RP2D) of MK2206 when administered orally $(\mathrm{PO})$ in the above combinations. Additional objectives were to explore the PK profile, antitumor activity of MK-2206 in combination and correlation of anti-tumor activity with tumor P13K pathway activation events.

\section{Materials and methods}

This phase 1, multi-arm, open-label, dose-escalation study (ClinicalTrials.gov: NCT00848718; http://clinicaltrials.gov/ ct2/show/NCT00848718) was conducted at 4 centers (Royal Marsden NHS Foundation Trust, Sutton, Surrey, UK; South Texas Accelerated Research Therapeutics [START], Texas, USA; Princess Margaret Hospital, Toronto, Ontario, Canada; H. Lee Moffitt Cancer Center and Research Institute, Tampa, Florida, USA). The study was conducted in accordance with the Declaration of Helsinki and Good Clinical Practice Guidelines of the International Conference on Harmonization and was approved by the Ethics Committees and Institutional Review Boards at all study sites. All patients provided written informed consent before any study procedures were performed.

\section{Eligibility criteria}

Patients 18 years or older with confirmed advanced solid tumors were eligible if they had progressed after standard therapy, or if no standard therapy was available for them; had Eastern Cooperative Oncology Group performance status $\leq 1$; surgery or chemotherapy within the previous 4 weeks; $\leq 3$ prior lines of cytotoxic therapies (arms 1 and 2 only); residual toxicity from prior treatment grade $\leq 1$; adequate bone marrow, renal, and hepatic function; and fasting serum glucose $\leq 1.1 \times$ the upper limit of normal and hemoglobin A1c (HbA1c) $\leq 8 \%$. Patients were excluded if they were diabetic and on antidiabetic therapy, pregnant or breastfeeding, receiving oral corticosteroids, had any condition(s) that would impede drug ingestion or absorption, or had other significant coexisting medical conditions. 


\section{Study design}

MK-2206 was initially administered PO every other day (QOD) on days 1, 3, 5, and 7 (days 1-7) of a 21-day cycle, in combination with intravenous (IV) carboplatin (area under the curve $6.0 \mathrm{mg} / \mathrm{mL}$ [AUC 6]) over 1 hour and IV paclitaxel $200 \mathrm{mg} / \mathrm{m}^{2}$ over 3 hours (arm 1; Table 1); or IV docetaxel $75 \mathrm{mg} / \mathrm{m}^{2}$ over 1 hour (arm 2; Table 1). MK-2206 was also administered QOD continuous with daily PO erlotinib $100 \mathrm{mg}$ or $150 \mathrm{mg}$ every 21 days; both MK-2206 and erlotinib were given on a 21-day cycle (arm 3; Table 1). Based on the MTD of single-agent MK-2206 of $60 \mathrm{mg}$ QOD, determined using a modified $3+3$ design [20], cohorts of 3 to 6 patients were to be treated at preplanned MK-2206 dose levels of $45 \mathrm{mg}$ and $60 \mathrm{mg}$, in combination with carboplatin and paclitaxel (arm 1) or docetaxel (arm 2), or with erlotinib (arm 3).

During dose escalation of the days 1-7 QOD dosing schedule of MK-2206, emerging data led to the introduction of 2 protocol amendments. First, data from the same schedule in the first-in-human phase 1 study demonstrated that MK-2206 had a long half-life $\left(\mathrm{t}_{1 / 2}\right)$ of 60 to 80 hours. The tolerability of a QW schedule was investigated and found to be acceptable with evidence of PD activity [17]. Preclinical efficacy studies had also demonstrated the antitumor effect of MK-2206 administered either QW or 3 times per week with daily erlotinib [19]. This suggested that continuous exposure with MK-2206 may not be necessary with erlotinib and that overall, more flexible dosing schedules can be used in

Table 1 MK-2206 treatment regimen by treatment arm

\begin{tabular}{|c|c|c|c|}
\hline $\begin{array}{l}\text { Treatment } \\
\text { arm }\end{array}$ & $\begin{array}{l}\text { MK-2206 } \\
\text { dose, } \mathrm{mg}\end{array}$ & Schedule $^{a}$ & Combination with: \\
\hline \multirow[t]{5}{*}{1} & 45 & \multirow[t]{2}{*}{ QOD } & \multirow{5}{*}{$\begin{array}{l}\text { Carboplatin (IV, AUC6, 1-hour } \\
\text { infusion) and paclitaxel } \\
\left(\mathrm{IV}, 200 \mathrm{mg} / \mathrm{m}^{2} \text {, 3-hour infusion }\right.\end{array}$} \\
\hline & 60 & & \\
\hline & 90 & \multirow[t]{3}{*}{ Q3W } & \\
\hline & 135 & & \\
\hline & 200 & & \\
\hline \multirow[t]{4}{*}{2} & 45 & QOD & $\begin{array}{c}\text { Docetaxel (IV, } 75 \mathrm{mg} / \mathrm{m}^{2}, \\
\text { 1-hour infusion) }\end{array}$ \\
\hline & 90 & \multirow[t]{3}{*}{ Q3W } & \multirow{3}{*}{$\begin{array}{c}\text { Docetaxel (IV, } 60 \mathrm{mg} / \mathrm{m}^{2} \\
\text { 1-hour infusion) }\end{array}$} \\
\hline & 135 & & \\
\hline & 200 & & \\
\hline \multirow[t]{4}{*}{3} & 45 & \multirow[t]{2}{*}{ QOD* } & Erlotinib (oral, 100 mg, QD) \\
\hline & 45 & & Erlotinib (oral, 150 mg, QD) \\
\hline & 135 & \multirow[t]{2}{*}{ QW } & Erlotinib (oral, 100 mg, QD) \\
\hline & 135 & & Erlotinib (oral, 150 mg, QD) \\
\hline
\end{tabular}

Abbreviations: IV intravenous, AUC6 area under the curve $6.0 \mathrm{mg} / \mathrm{mL}$, $Q D$ once daily.

${ }^{\mathrm{a}} \mathrm{QOD}=$ once every other day on days $1,3,5$, and 7 of 21-day cycle, except *: alternate day dosing on days $1-21 ; \mathrm{Q} 3 \mathrm{~W}=$ once every 3 weeks on day 1 of 21-day cycle; QW = once weekly on days 1, 8, and 15 of 21-day cycle. combinations [18]. Second, 3 DLTs of febrile neutropenia were reported at the first dose level of $45 \mathrm{mg}$ MK-2206 QOD with IV docetaxel at $75 \mathrm{mg} / \mathrm{m}^{2}$. Consequently, 2 schedules (QW and Q3W) for MK-2206 were added to the current study (Table 1). Fasted patients received MK-2206 as 5-mg, 25-mg, or 200-mg tablets with chemotherapy or erlotinib. The dose-escalation phase in all schedules followed a toxicity probability interval approach, where the aim was to target a dose with a DLT rate of $30 \%$ [20]. Patients could continue receiving single-agent MK-2206 after completing chemotherapy or erlotinib doses.

\section{Safety}

For all treatment schedules, safety assessments were conducted at baseline and on days 1, 2, 3, 7, 15, and 21 of cycle 1 , and weekly in cycles 2 to 6 . From cycle 7 onwards, safety assessments were performed on day 1 of each cycle. All patients had a history, physical examination including full ophthalmologic assessment, electrocardiogram, hematology and chemistry profiling, and urine analysis performed at baseline. In addition to glucose monitoring, serum c-peptide and whole blood HbA1c were measured at baseline and monthly. Adverse events (AEs) and laboratory variables were assessed using the National Cancer Institute Common Terminology Criteria for Adverse Events (NCI-CTCAE) version $3.0^{1}$.

A DLT was defined as any of the following occurring during the first cycle of treatment: grade 4 neutropenia lasting $\geq 7$ days; grade 3 or 4 neutropenia with fever $\geq 38.5^{\circ} \mathrm{C}$ and/or infection requiring therapy; grade 4 thrombocytopenia; any drug-related AE that led to dose modification of MK-2206 or erlotinib; unresolved drug-related toxicity regardless of grade that resulted in a 3-week or longer delay of the start of cycle 2; persistent increase in QTc interval (>60 ms from baseline and/or >500 ms); clinically significant bradycardia; and any grade 3-5 nonhematologic toxicity with the exception of, in the opinion of the investigator, grade 3 nausea, vomiting, diarrhea, dehydration or hyperglycemia in the setting of inadequate compliance with supportive care treatment, alopecia, inadequately treated hypersensitivity reaction, and grade 3 elevated transaminases lasting 1 week or less.

\section{Pharmacokinetic analyses}

In arms 1 and 2, for days 1-7 QOD dosing, blood sampling for MK-2206 PK was performed in cycle 1 on day 1 (predose, 2, 4, 6, 10, and 24 hours postdose), day 3 (48 hours postdose), day 7 (predose and 4 hours postdose), and days 15 and 21 (same time as day 1 predose sampling). For the Q3W schedule, samples were taken in cycle 1 on days 1 to 3 as per the QOD schedule, then on days 5, 7, 15, and in cycle 2 on day 1 . Blood samples were collected predose and just before the end of the infusion for carboplatin, 
paclitaxel, and docetaxel for archival and possible PK analysis. Another sample was taken 30 minutes into the infusion of paclitaxel. These samples were archived for possible future analysis to investigate if any unexpected toxicities may have been as a result of a PK interaction. Docetaxel PK samples were analyzed in view of the DLT of febrile neutropenia observed in arm 2; however, PK parameters, such as half-life $\left(t_{1 / 2}\right)$ or systemic exposure of paclitaxel, docetaxel, carboplatin, and erlotinib, could not be evaluated due to the sparse blood sampling design used in this study.

In arm 3, for MK-2206 PK analysis in the QOD schedule, sampling was performed in cycle 1 on days 1 and 3 as in arms 1 and 2, then on days 7 and 15 (predose), day 21 (predose, 2, 4, 6, and 10 hours postdose), and in cycle 2 on days 1 and 2 (predose). For QW dosing, samples were taken in cycle 1 on day 1 (predose, 2, 4, 6, 10, and 24 hours postdose), day 3 (48 hours postdose), and day 5 (96 hours postdose), then on days 8 and 15 (predose). This sampling schedule was repeated in cycle 2, except for the day 15 predose sample, which was omitted. For the QOD schedule, PK sampling for erlotinib was performed in cycle 1 on day 1 (predose, 2 and 4 hours postdose) and day 21 (2 and 4 hours postdose); for the QW schedule, sampling was performed in cycle 1 on day 1 (predose, 2 and 4 hours postdose) and in cycle 2 on day 1 ( 2 and 4 hours postdose). Blood samples for MK-2206 PK were obtained, processed, and analyzed as described [18]. Blood samples were not analyzed for erlotinib concentrations as the potential for a marked drug-drug interaction with erlotinib as a victim was considered to be low as erlotinib is metabolized by both CYP3A and CYP1A. In addition, the CYP3A induction or inhibition potential of MK-2206 is low at the clinical concentrations achieved in this study, although the effect of MK-2206 on CYP1A is unknown.

\section{Biomarker studies}

Circulating nucleic acids were analyzed for PIK3CA (exons 9 and 20), KRAS (exons 2 and 3), and BRAF (exons 11 and 15) mutations. DNA extracted from whole blood samples was subjected to real-time quantitative polymerase chain reaction and spectrophotometric analysis as part of the quality control process, as previously described [21]. Mutation screening was performed using Surveyor Nuclease (Transgenomic, Inc., Nebraska, USA).

\section{Tumor response}

Radiologic assessment (computed tomography [CT] and/or magnetic resonance imaging [MRI] scans) of disease status was performed at baseline and every 6 weeks according to Response Evaluation Criteria in Solid Tumors (v1.0) [22]. Relevant markers were used to assess the effects of MK-2206 combination therapy on various tumor types.

\section{Results}

Seventy-two patients were treated between April 2009 and May 2012 (Table 2)-however, full accrual to the protocol was suspended due to a change in the developmental plans of MK-2206. In arm 1, 31 patients received a median of 3 cycles (range 1-10) of combination therapy; 10 of these patients went on to receive single-agent MK-2206 and completed a median of 4 cycles of treatment (range 1-15). In arm 2, 16 patients received a median of 3 cycles (range 1-7) with 1 of these patients receiving 1 further cycle of MK-2206 only. Another 25 patients received a median of 5 cycles (range 1-12) in arm 3 of the study.

\section{Dose-limiting toxicities and maximum tolerated dose}

The MTD for all of the combinations could not be determined according to the predefined protocol criteria based on the number of patients enrolled at the time of study discontinuation-in cases where higher dose levels

\section{Table 2 Patient characteristics}

\begin{tabular}{|c|c|}
\hline Characteristic & $\begin{array}{l}\text { Patients } \\
(\mathrm{N}=72)\end{array}$ \\
\hline \multicolumn{2}{|l|}{ Age, years } \\
\hline Median (SD) & $58.0(12.4)$ \\
\hline Range & $23-78$ \\
\hline \multicolumn{2}{|l|}{ Gender, n (\%) } \\
\hline Male & $36(50.0)$ \\
\hline Female & $36(50.0)$ \\
\hline \multicolumn{2}{|l|}{ ECOG PS, n (\%) } \\
\hline 0 & $22(31)$ \\
\hline 1 & $49(68)$ \\
\hline Not recorded & $1(1)$ \\
\hline \multicolumn{2}{|l|}{ Tumor type, n (\%) } \\
\hline NSCLC & $13(18.0)$ \\
\hline Breast & $10(13.8)$ \\
\hline Melanoma & $6(8.3)$ \\
\hline Pancreas & $5(6.9)$ \\
\hline Prostate & $4(5.6)$ \\
\hline Colon & $4(5.6)$ \\
\hline Esophagus & $3(4.2)$ \\
\hline Parotid & $3(4.2)$ \\
\hline $\mathrm{SCLC}$ & $3(4.2)$ \\
\hline Other $^{a}$ & $21(29.2)$ \\
\hline
\end{tabular}

Abbreviations: SD standard deviation, ECOG Eastern Cooperative Oncology Group, PS performance status, SCLC small cell lung cancer, SCC squamous cell cancer.

${ }^{a}$ Cervical, cholangiocarcinoma, gastric, mesothelioma, endothelial cell, bladder, renal, sarcoma, SCC orbit, SCC vagina, SCC vulva, anal, tonsil, hard palate, and vulva. 
were not explored a maximum administered dose (MAD) was determined. Dose-escalation levels and DLTs are summarized in Table 3.

\section{QOD dosing schedule}

In arm 1, preplanned dose escalation from 45 to $60 \mathrm{mg}$ was achieved; DLTs were rash (1 of 5 at $45 \mathrm{mg}$ and 1 of 4 at $60 \mathrm{mg}$; Figure 1A and 1B) and febrile neutropenia (2 of 4 at $60 \mathrm{mg}$ ). All episodes of rash were fully reversible within 7 to 14 days after dose interruption and appropriate treatment. The MTD of MK-2206 was established as $45 \mathrm{mg} \mathrm{PO}$, when administered on the QOD dose schedule on days 1, 3, 5, and 7, with carboplatin AUC 6 and paclitaxel $200 \mathrm{mg} / \mathrm{m}^{2}$. In arm 2, when MK-2206 was administered at $45 \mathrm{mg}$ days 1-7 QOD with docetaxel $75 \mathrm{mg} / \mathrm{m}^{2}, 3$ of 5 patients experienced a DLT of febrile neutropenia. In arm 3, DLTs were rash and stomatitis (2 of 8 at MK-2206 $45 \mathrm{mg}$ with erlotinib $100 \mathrm{mg} ; 1$ of 3 at MK-2206 $45 \mathrm{mg}$ with erlotinib $150 \mathrm{mg}$ ). The rash seen in patients treated with MK-2206 and erlotinib was a combination of the acneiform pattern seen with erlotinib and the maculopapular pattern associated with MK-2206 (Figure 1C). Based on MK-2206 single-agent PK data and the high incidence of febrile neutropenia in arm 2 with docetaxel $75 \mathrm{mg} / \mathrm{m}^{2}$, a decision was made to reduce the dose of docetaxel to $60 \mathrm{mg} / \mathrm{m}^{2}$ and investigate QW and Q3W schedules.

\section{Q3W and QW dosing schedules}

In arms 1 and 2, dose escalation through 3 dose levels administered Q3W (90, 135, and $200 \mathrm{mg}$ ) was achieved.
In arm 1, DLTs were rash in 1 of 5 and 2 of 5 patients at $90 \mathrm{mg}$ and $200 \mathrm{mg}$, respectively, and thrombocytopenia in 1 of 5 patients at $135 \mathrm{mg}$. Therefore, the MTD of Q3W MK-2206 dosing in combination with carboplatin and paclitaxel was $135 \mathrm{mg}$. In arm 2, the only DLT was tinnitus in 1 of 4 patients at MK-2206 $200 \mathrm{mg}$ with a reduced dose of docetaxel at $60 \mathrm{mg} / \mathrm{m}^{2}$. The combination was not to be investigated further, so this dose level was defined as the MAD; the MTD was not reached. In arm 3, $135 \mathrm{mg}$ MK-2206 administered QW was tested with erlotinib $100 \mathrm{mg}$ and $150 \mathrm{mg}$, with 1 DLT of rash observed in 5 patients at the higher dose level of erlotinib. As DLTs were low (17\%), the MTD of MK-2206 in this combination was not reached. The MAD was defined as MK-2206 135 mg QW with erlotinib 150 mg.

\section{Safety and tolerability}

Overall, the treatment combinations were well-tolerated, with a low incidence of grade 3 or 4 AEs. The most common AEs were similar across the arms and schedulesfatigue (68\%), nausea (49\%), rash (47\%), diarrhea (44\%), anorexia (44\%), alopecia (40\%), vomiting (36\%), stomatitis (32\%), and hyperglycemia (25\%; $8 \%$ considered drugrelated). Hyperglycemia was transient, grade $1 / 2$, and largely associated with steroid premedication in arms 1 and 2. In arm 1, rash was observed more frequently with the days 1-7 QOD dose schedule (40\%) compared with the Q3W schedule (25\%). In arm 2, the frequency of febrile neutropenia decreased with dose reduction of docetaxel and change to Q3W dosing for MK-2206. There were no appreciable differences in the frequency of AEs

Table 3 Dose schedules and dose-limiting toxicities of MK-2206 in combination therapy

\begin{tabular}{|c|c|c|c|c|}
\hline \multicolumn{2}{|c|}{ Treatment arm } & \multirow{2}{*}{$\begin{array}{c}\text { MK-2206 dosing schedule } \\
45 \mathrm{mg} \mathrm{QOD}{ }^{\mathrm{b}}\end{array}$} & \multirow{2}{*}{$\begin{array}{c}\text { Evaluable patients } \\
5\end{array}$} & \multirow{2}{*}{$\begin{array}{l}\text { Dose-limiting toxicities } \\
1 ; \text { rash }\end{array}$} \\
\hline 1 & Carboplatin AUC 6 & & & \\
\hline & & $60 \mathrm{mg} \mathrm{QOD}^{\mathrm{b}}$ & 4 & $3^{\mathrm{a}}$; rash, febrile neutropenia (2) \\
\hline & & $90 \mathrm{mg}$ Q3W & 5 & $1 ;$ rash \\
\hline & Paclitaxel $200 \mathrm{mg} / \mathrm{m}^{2}$ & & & \\
\hline & & $135 \mathrm{mg}$ Q3W & 5 & $1 ; \mathrm{TCP}$ \\
\hline & & $200 \mathrm{mg}$ Q3W & 5 & $2 ;$ rash \\
\hline \multirow[t]{4}{*}{2} & Docetaxel $75 \mathrm{mg} / \mathrm{m}^{2}$ & $45 \mathrm{mg}$ QOD ${ }^{\mathrm{b}}$ & 5 & 3; febrile neutropenia \\
\hline & Docetaxel $60 \mathrm{mg} / \mathrm{m}^{2}$ & $90 \mathrm{mg}$ Q3W & 3 & 0 \\
\hline & & 135 mg Q3W & 3 & 0 \\
\hline & & $200 \mathrm{mg}$ Q3W & 4 & 1; tinnitus \\
\hline \multirow[t]{4}{*}{3} & Erlotinib $100 \mathrm{mg}$ & $45 \mathrm{mg} \mathrm{QOD}^{\mathrm{C}}$ & 8 & 2; rash, stomatitis \\
\hline & & $135 \mathrm{mg} \mathrm{QW}$ & 4 & 0 \\
\hline & Erlotinib $150 \mathrm{mg}$ & $45 \mathrm{mg} \mathrm{QOD}^{\mathrm{C}}$ & 3 & 1 ; rash \\
\hline & & $135 \mathrm{mg} \mathrm{QW}$ & 5 & $1 ;$ rash \\
\hline
\end{tabular}

Abbreviation: TCP thrombocytopenia.

${ }^{\mathrm{a}} 3$ events in 2 patients.

bdays 1-7.

continuous. 

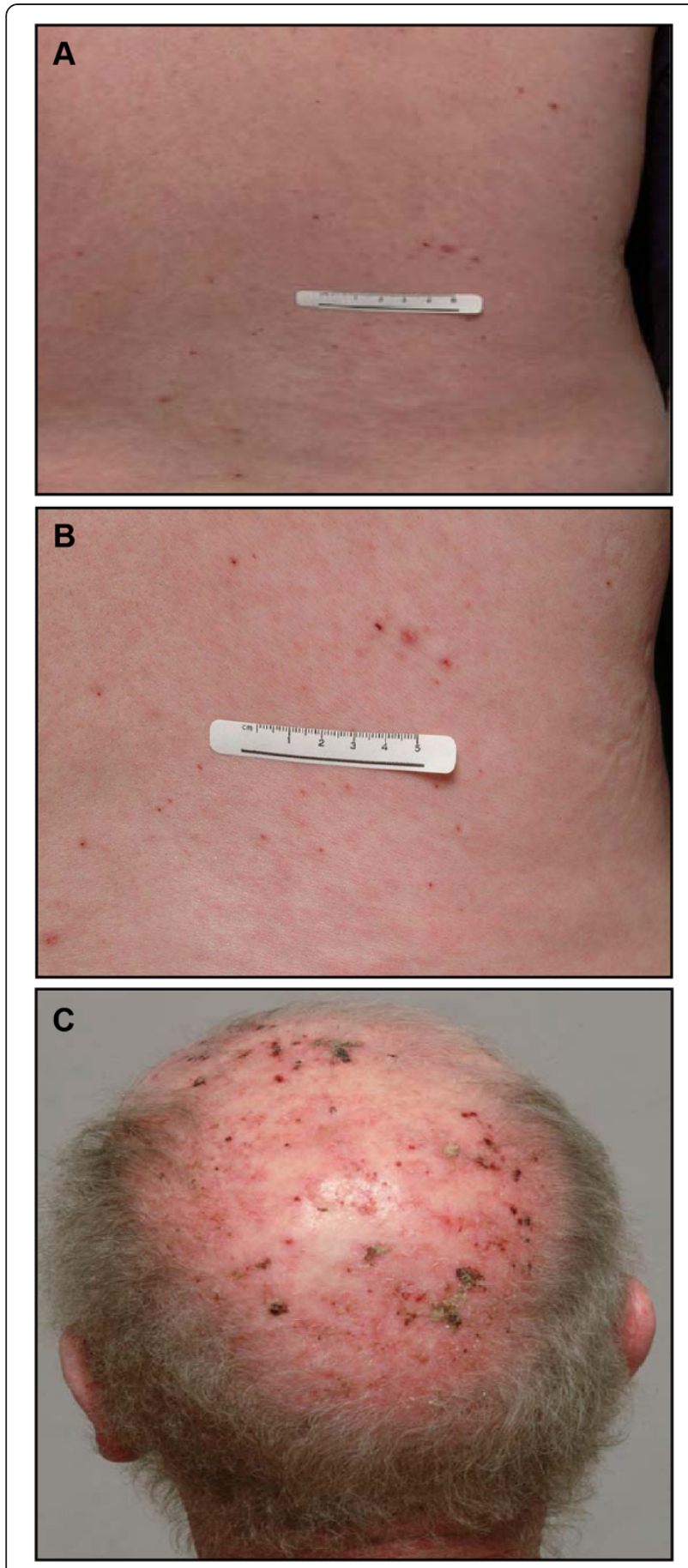

Figure 1 Patterns of drug induced rash. The typical rash associated with MK-2206 was a widespread, reversible, generalized, erythematous, maculopapular, non-acneiform rash (A and B). In arm 3, some patients also demonstrated an acneiform rash affecting the head, face, neck, and trunk, in addition to the maculopapular MK-2206 related rash (C).

between the QOD and QW schedules in arm 3. In arm 3 however, chronic anorexia, fatigue, rash and diarrhea, albeit at grade $1 / 2$, were prominent. Table 4 summarizes treatment-related AEs observed by treatment arm and NCI-CTCAE grade.

\section{Pharmacokinetics}

Pharmacokinetic data for MK-2206 were available from 70 patients: 30 from arm 1, 15 from arm 2, and 25 from arm 3. Across all treatment arms, AUC, maximum plasma concentration $\left(\mathrm{C}_{\max }\right)$, and time to maximum concentration $\left(\mathrm{T}_{\max }\right)$ values following the first MK-2206 dose were within ranges observed at the corresponding dose levels in the single-agent phase 1 study [18]. However, due to insufficient PK sampling, steady-state exposure in combination with either carboplatin and paclitaxel, docetaxel or erlotinib could not be assessed. The apparent $t_{1 / 2}$ of MK-2206 in combination with carboplatin and erlotinib was consistent with that observed with monotherapy. Table 5 shows the key PK parameters for MK-2206 at 45-mg, 60-mg, 90-mg, and 135-mg dose levels in this combination therapy study after the first dose. The mean 48-hr plasma concentrations of MK-2206 at the 45-mg QOD (arm 3), 60-mg QOD (arm 1), and 135-mg QW (arm 3) dose levels were above $56.8 \mathrm{nM}$, at the last PK sampling time corresponding to $70 \%$ AKT inhibition in the single-agent phase 1 study [18].

An analysis of docetaxel PK samples did not indicate a PK cause for the higher-than-expected frequency of febrile neutropenia DLTs in arm 2: the mean end-of-infusion concentration value was $3.01 \mu \mathrm{g} / \mathrm{mL}$. This is within the range of mean values of 1.68 to $4.06 \mu \mathrm{g} / \mathrm{mL}$ reported in the literature [23-25]. Paclitaxel, erlotinib, and carboplatin plasma samples were not assayed. Paclitaxel is metabolized by CYP3A and CYP2C, while erlotinib is metabolized primarily by CYP3A and CYP1A. The major drug-metabolizing enzyme for docetaxel is CYP3A; thus, docetaxel is vulnerable to CYP3A-mediated drug-drug interactions, while carboplatin undergoes renal excretion and hepatic metabolism equally, reducing its potential to be a victim of CYP-mediated DDIs. MK-2206 is not a significant inhibitor or inducer of major CYP enzymes (IC50 >35 $\mu \mathrm{M}$ for CYP3A4, 2C9, and 2D6 inhibition, and has insignificant effect on CYP3A mRNA and activity at 0.1 to $10 \mu \mathrm{M}$ ); therefore, MK-2206 is not expected to perpetuate significant drug-drug interactions at the clinical doses. MK-2206 is susceptible as a victim to CYP3Amediated drug-drug interaction as metabolism of MK2206 to oxidative metabolites in human microsomes is mediated primarily by CYP3A. Exposure of MK-2206 after co-administration with erlotinib did not suggest a substantial PK interaction of MK-2206 as a victim, although attainment of a steady state of MK-2206 could not be confirmed at the last PK sampling. Steady-state exposure of MK-2206 in combination with either carboplatin and paclitaxel or docetaxel are not available based on the study design used. 
Table 4 Treatment-related adverse events occurring in $\geq 20 \%$ of patients in any treatment arm with QOD and Q3W dosing schedules of MK-2206

\begin{tabular}{|c|c|c|c|c|c|c|c|c|c|c|c|c|c|}
\hline \multirow{5}{*}{$\begin{array}{l}\text { Adverse event, } \\
\text { n (\%) }\end{array}$} & \multirow{2}{*}{\multicolumn{5}{|c|}{$\begin{array}{c}\text { Arm 1: carboplatin AUC 6; } \\
\text { Paclitaxel } 200 \mathrm{mg} / \mathrm{m}^{2}\end{array}$}} & \multicolumn{4}{|c|}{ Arm 2: docetaxel } & \multirow{2}{*}{\multicolumn{4}{|c|}{$\begin{array}{c}\text { Arm 3: erlotinib } \\
100 \mathrm{mg} \text { and } 150 \mathrm{mg}\end{array}$}} \\
\hline & & & & & & \multirow{4}{*}{$\begin{array}{c}75 \mathrm{mg} / \mathrm{m}^{2} \\
M K-2206 \\
\mathrm{QOD}^{\mathrm{a}} \\
45 \mathrm{mg} \\
(\mathrm{n}=5)\end{array}$} & \multirow{3}{*}{\multicolumn{3}{|c|}{$\begin{array}{c}60 \mathrm{mg} / \mathrm{m}^{2} \\
\mathrm{MK}-2206 \\
\mathrm{Q}^{2} \mathrm{~W}^{\mathrm{b}}\end{array}$}} & & & & \\
\hline & \multirow{2}{*}{\multicolumn{2}{|c|}{$\begin{array}{c}\text { MK-2206 } \\
\text { QOD }\end{array}$}} & \multirow{2}{*}{\multicolumn{3}{|c|}{$\begin{array}{c}\text { MK-2206 } \\
\text { Q3W }\end{array}$}} & & & & & \multirow{3}{*}{$\begin{array}{c}\text { MK-2206 } \\
\text { QOD } \\
45 \mathrm{mg}^{\mathrm{c}} \\
(\mathrm{n}=9)\end{array}$} & \multirow{2}{*}{\multicolumn{3}{|c|}{$\begin{array}{l}\text { MK-2206 } \\
\text { QW }\end{array}$}} \\
\hline & & & & & & & & & & & & & \\
\hline & $\begin{array}{l}45 \mathrm{mg} \\
(\mathrm{n}=6)\end{array}$ & $\begin{array}{l}60 \mathrm{mg} \\
(\mathrm{n}=9)\end{array}$ & $\begin{array}{l}90 \mathrm{mg} \\
(\mathrm{n}=5)\end{array}$ & $\begin{array}{l}135 \mathrm{mg} \\
(\mathrm{n}=5)\end{array}$ & $\begin{array}{c}200 \mathrm{mg} \\
(\mathrm{n}=6)\end{array}$ & & $\begin{array}{l}90 \mathrm{mg} \\
(\mathrm{n}=3)\end{array}$ & $\begin{array}{c}135 \mathrm{mg} \\
(\mathrm{n}=4)\end{array}$ & $\begin{array}{c}200 \mathrm{mg} \\
(\mathrm{n}=4)\end{array}$ & & $\begin{array}{l}45 \mathrm{mg}^{\mathrm{d}} \\
(\mathrm{n}=4)\end{array}$ & $135 \mathrm{mg}^{\mathrm{c}}(\mathrm{n}=6)$ & $\begin{array}{c}135 \mathrm{mg}^{\mathrm{d}} \\
(\mathrm{n}=6)\end{array}$ \\
\hline \multicolumn{14}{|l|}{ Fatigue } \\
\hline Grade 1/2 & $5(83)$ & $6(66)$ & $4(80)$ & $4(80)$ & $1(17)$ & $4(80)$ & $3(100)$ & $2(50)$ & $4(100)$ & $4(44)$ & $3(75)$ & $4(66)$ & $3(50)$ \\
\hline Grade 3 & 0 & 0 & 0 & $1(20)$ & 0 & 0 & 0 & 0 & 0 & $1(11)$ & 0 & 0 & $1(17)$ \\
\hline Grade 4 & 0 & 0 & 0 & 0 & 0 & 0 & 0 & 0 & 0 & 0 & 0 & 0 & 0 \\
\hline \multicolumn{14}{|l|}{ Nausea } \\
\hline Grade 1/2 & $3(50)$ & $5(55)$ & $3(60)$ & $2(40)$ & $4(66)$ & $2(40)$ & $1(33)$ & $1(25)$ & $2(50)$ & $2(22)$ & $4(100)$ & $1(17)$ & $2(33)$ \\
\hline Grade 3 & 0 & $1(11)$ & $1(20)$ & 0 & 0 & 0 & 0 & 0 & 0 & $1(11)$ & 0 & 0 & 0 \\
\hline Grade 4 & 0 & 0 & 0 & 0 & 0 & 0 & 0 & 0 & 0 & 0 & 0 & 0 & 0 \\
\hline \multicolumn{14}{|l|}{ Rash } \\
\hline Grade 1/2 & $3(50)$ & $1(11)$ & 0 & $1(20)$ & $1(17)$ & $4(80)$ & $2(66)$ & 0 & $1(25)$ & $3(33)$ & $1(25)$ & $4(66)$ & $5(83)$ \\
\hline Grade 3 & $1(17)$ & $1(11)$ & $1(20)$ & 0 & $1(17)$ & 0 & 0 & 0 & 0 & $2(22)$ & $2(50)$ & 0 & 0 \\
\hline Grade 4 & 0 & 0 & 0 & 0 & 0 & 0 & 0 & 0 & 0 & 0 & 0 & 0 & 0 \\
\hline \multicolumn{14}{|l|}{ Decreased appetite } \\
\hline Grade 1/2 & $2(33)$ & $5(55)$ & $2(40)$ & $2(40)$ & $2(33)$ & $2(40)$ & 0 & $2(50)$ & $1(25)$ & $1(11)$ & $4(100)$ & $3(50)$ & $5(83)$ \\
\hline Grade 3 & 0 & 0 & 0 & $1(20)$ & 0 & 0 & 0 & 0 & 0 & $1(11)$ & 0 & 0 & 0 \\
\hline Grade 4 & 0 & 0 & 0 & 0 & 0 & 0 & 0 & 0 & 0 & 0 & 0 & 0 & 0 \\
\hline \multicolumn{14}{|l|}{ Diarrhea } \\
\hline Grade 1/2 & $1(17)$ & $4(44)$ & $2(40)$ & $1(20)$ & $2(33)$ & $1(20)$ & $2(66)$ & 0 & $2(50)$ & $4(44)$ & $3(75)$ & $4(66)$ & $5(83)$ \\
\hline Grade 3 & 0 & 0 & 0 & 0 & 0 & 0 & 0 & 0 & 0 & $1(11)$ & 0 & 0 & 0 \\
\hline Grade 4 & 0 & 0 & 0 & 0 & 0 & 0 & 0 & 0 & 0 & 0 & 0 & 0 & 0 \\
\hline \multicolumn{14}{|l|}{ Alopecia } \\
\hline Grade 1/2 & $4(66)$ & $6(66)$ & $5(100)$ & $4(80)$ & $2(33)$ & $3(60)$ & $1(33)$ & $1(25)$ & $2(50)$ & 0 & 0 & $1(17)$ & 0 \\
\hline Grade 3 & 0 & 0 & 0 & 0 & 0 & 0 & 0 & 0 & 0 & 0 & 0 & $1(17)$ & 0 \\
\hline Grade 4 & 0 & 0 & 0 & 0 & 0 & 0 & 0 & 0 & 0 & 0 & 0 & 0 & 0 \\
\hline \multicolumn{14}{|l|}{ Vomiting } \\
\hline Grade 1/2 & $1(17)$ & $3(33)$ & 0 & $3(60)$ & $4(66)$ & $3(60)$ & $1(33)$ & $1(25)$ & $1(25)$ & $4(44)$ & $1(25)$ & $1(17)$ & 0 \\
\hline Grade 3 & 0 & $1(11)$ & $1(20)$ & 0 & 0 & 0 & 0 & 0 & 0 & 0 & 0 & $1(17)$ & 0 \\
\hline Grade 4 & 0 & 0 & 0 & 0 & 0 & 0 & 0 & 0 & 0 & 0 & 0 & 0 & 0 \\
\hline
\end{tabular}


Table 4 Treatment-related adverse events occurring in $\geq \mathbf{2 0 \%}$ of patients in any treatment arm with QOD and Q3W dosing schedules of MK-2206 (Continued)

\begin{tabular}{|c|c|c|c|c|c|c|c|c|c|c|c|c|c|}
\hline \multicolumn{14}{|l|}{ Anemia } \\
\hline Grade 1/2 & $1(17)$ & $1(11)$ & $2(40)$ & $1(20)$ & $1(17)$ & $2(40)$ & 0 & $1(25)$ & $1(25)$ & $2(22)$ & 0 & 0 & $2(33)$ \\
\hline Grade 3 & 0 & $3(33)$ & $1(20)$ & $1(20)$ & 0 & 0 & 0 & 0 & 0 & 0 & 0 & $1(17)$ & 0 \\
\hline Grade 4 & $1(17)$ & $1(11)$ & 0 & $1(20)$ & 0 & 0 & 0 & 0 & 0 & 0 & 0 & 0 & $1(17)$ \\
\hline \multicolumn{14}{|l|}{ Stomatitis } \\
\hline Grade 1/2 & $1(17)$ & $2(22)$ & $2(40)$ & $1(20)$ & $1(17)$ & $2(40)$ & 0 & $1(25)$ & 0 & $3(33)$ & $1(25)$ & $4(66)$ & $4(66)$ \\
\hline Grade 3 & 0 & 0 & 0 & 0 & 0 & 0 & 0 & 0 & 0 & $1(11)$ & 0 & 0 & 0 \\
\hline Grade 4 & 0 & 0 & 0 & 0 & 0 & 0 & 0 & 0 & 0 & 0 & 0 & 0 & 0 \\
\hline \multicolumn{14}{|l|}{ Neutropenia } \\
\hline Grade 1/2 & 0 & 0 & 0 & 0 & 0 & 0 & 0 & 0 & 0 & 0 & 0 & 0 & 0 \\
\hline Grade 3 & 0 & $2(22)$ & $2(40)$ & $1(20)$ & $1(17)$ & $1(20)$ & $1(33)$ & 0 & 0 & 0 & 0 & 0 & 0 \\
\hline Grade 4 & $1(17)$ & $3(33)$ & $2(40)$ & $2(40)$ & 0 & $2(40)$ & $1(33)$ & 0 & $1(25)$ & 0 & 0 & 0 & 0 \\
\hline \multicolumn{14}{|l|}{ Leukopenia } \\
\hline Grade 1/2 & $1(17)$ & $3(33)$ & 0 & $1(20)$ & 0 & 0 & $1(33)$ & 0 & $1(25)$ & 0 & 0 & 0 & 0 \\
\hline Grade 3 & 0 & $1(11)$ & $4(80)$ & $2(40)$ & $1(17)$ & 0 & 0 & 0 & 0 & 0 & 0 & 0 & 0 \\
\hline Grade 4 & 0 & $2(22)$ & 0 & $1(20)$ & 0 & $1(20)$ & 0 & 0 & 0 & 0 & 0 & 0 & 0 \\
\hline \multicolumn{14}{|c|}{ Thrombocytopen-ia } \\
\hline Grade 1/2 & 0 & $4(44)$ & $1(20)$ & $1(20)$ & $1(17)$ & $2(40)$ & $1(33)$ & 0 & 0 & 0 & 0 & 0 & $1(17)$ \\
\hline Grade 3 & $1(17)$ & $1(11)$ & $1(20)$ & 0 & 0 & 0 & 0 & 0 & 0 & 0 & 0 & 0 & 0 \\
\hline Grade 4 & 0 & 0 & 0 & $2(40)$ & 0 & 0 & 0 & 0 & 0 & 0 & 0 & 0 & 0 \\
\hline \multicolumn{14}{|l|}{ Pruritus } \\
\hline Grade 1/2 & $4(66)$ & 0 & 0 & $1(20)$ & $1(17)$ & $2(40)$ & 0 & 0 & 0 & $3(33)$ & 0 & $2(33)$ & $2(33)$ \\
\hline Grade 3 & 0 & 0 & 0 & 0 & 0 & 0 & 0 & 0 & 0 & 0 & 0 & $1(17)$ & 0 \\
\hline Grade 4 & 0 & 0 & 0 & 0 & 0 & 0 & 0 & 0 & 0 & 0 & 0 & 0 & 0 \\
\hline
\end{tabular}

aMK-2206 QOD explored with docetaxel $75 \mathrm{mg} / \mathrm{m}^{2}$ only.

${ }^{b} \mathrm{MK}-2206$ Q3W explored with docetaxel $60 \mathrm{mg} / \mathrm{m}^{2}$ only.

${ }^{\mathrm{c}} 100 \mathrm{mg}$ erlotinib. 
Table 5 Pharmacokinetic parameters of MK-2206 after the first dose when administered in combination therapy

\begin{tabular}{|c|c|c|c|c|c|c|c|}
\hline & Treatment arm & MK-2206 dosing schedule & Number of patients & $A \cup C_{0-48 h}, n M \cdot h^{a}$ & $\mathrm{C}_{\max }, \mathrm{nM}^{\mathrm{a}}$ & $T_{\max }, h^{b}$ & $t_{1 / 2}, h^{c}$ \\
\hline \multirow[t]{5}{*}{1} & \multirow{5}{*}{$\begin{array}{l}\text { Carboplatin AUC } 6 \\
\text { Paclitaxel } 200 \text { mg/m² }\end{array}$} & $45 \mathrm{mg}$ QOD & 6 & $1630 \pm 496(30.4)$ & $57.7 \pm 13.8(23.9)$ & $4.0(4.0-6.0)$ & NA \\
\hline & & $60 \mathrm{mg}$ QOD & 8 & $2700 \pm 619(23.0)$ & $88.3 \pm 24.2(27.4)$ & $8.0(6.0-10.0)$ & NA \\
\hline & & 90 mg Q3W & 5 & $4130 \pm 1520$ & $144 \pm 57.0$ (39.6) & $6.0(4.0-10.0)$ & $79.5 \pm 17.3$ \\
\hline & & 135 mg Q3W & 6 & $7600 \pm 1280(15.3)$ & $255 \pm 50.9(6.8)$ & $8.0(6.0-10.0)$ & $73.0 \pm 20.0$ \\
\hline & & 200 mg Q3W & 5 & $9800 \pm 2550(25.9)$ & $458 \pm 268(58.5)$ & $4.0(4.0-10.0)$ & $74.7 \pm 13.4$ \\
\hline \multirow[t]{4}{*}{2} & Docetaxel 75 mg/m² & $45 \mathrm{mg}$ QOD & 5 & $1320 \pm 395(30.0)$ & $42.9 \pm 13.3(30.9)$ & $6.0(4.0-10.0)$ & NA \\
\hline & Docetaxel 60 mg/m² & 90 mg Q3W & 3 & $3000 \pm 1250(41.7)$ & $106 \pm 42.5(40.2)$ & $4.0(4.0-10.0)$ & $105.4 \pm 15.0$ \\
\hline & & 135 mg Q3W & 3 & $8090 \pm 542(6.7)$ & $278 \pm 35.5(12.8)$ & $6.0(4.0-10.0)$ & $106.1 \pm 32.7$ \\
\hline & & 200 mg Q3W & 4 & $7690 \pm 1550(20.1)$ & $287 \pm 67.6(23.5)$ & $6.0(4.0-6.0)$ & $86.9 \pm 11.5$ \\
\hline \multirow[t]{4}{*}{3} & Erlotinib 100 mg & $45 \mathrm{mg}$ QOD & 9 & $1460 \pm 417(28.6)$ & $48.8 \pm 11.2(23.0)$ & $6.0(4.0-10.0)$ & NA \\
\hline & & 135 mg QW & 6 & $6420 \pm 2760(42.9)$ & $212 \pm 75.9(35.8)$ & $6.0(2.0-6.0)$ & $60.6 \pm 6.6$ \\
\hline & Erlotinib 150 mg QD & $45 \mathrm{mg}$ QOD & 4 & $2110 \pm 637(30.2)$ & $65.6 \pm 29.3(44.6)$ & $7.0(4.0-24.0)$ & NA \\
\hline & & $135 \mathrm{mg} \mathrm{QW}$ & 6 & $6560 \pm 2650(40.2)$ & $244 \pm 84.2(34.5)$ & $4.0(4.0-10.0)$ & $50.2 \pm 10.3$ \\
\hline
\end{tabular}

Abbreviations: $A U C_{0-48 h}$ area under the curve from 0 to 48 hours, $C_{\max }$ maximum concentration, $T_{\max }$ time to maximum concentration, $Q 21$ every 21 days, $N A$ not available, $S D$ standard deviation.

${ }^{a}$ Mean \pm SD (coefficient of variation\%).

${ }^{\mathrm{b}}$ Median (range).

${ }^{\mathrm{C}}$ Harmonic mean \pm pseudo SD.

\section{Antitumor activity and biomarker analysis}

Sixty patients were evaluable for response ( $\operatorname{arm} 1, \mathrm{n}=24$; arm 2, $\mathrm{n}=13$; $\operatorname{arm} 3, \mathrm{n}=23$ ). In arm 1, a complete response was observed in 1 patient with squamous cell carcinoma (SCC) of the orbit who had progressed through previous cisplatin, cetuximab, and 5-fluorouracil therapy (Figure 2A). Four patients treated on both the days 1-7 QOD and Q3W schedules in arm 1 had confirmed partial responses (PR; melanoma, neuroendocrine prostate, endometrial, and cervical), and 2 patients had unconfirmed PRs (SCC of the head and neck, and gastric; Figure 2B). The patient with neuroendocrine prostate cancer had previously had a best response of stable disease (SD) with carboplatin and etoposide, while the patient with endometrial cancer had demonstrated SD with carboplatin and paclitaxel. The median duration of PR was 11 months (range 2-21 months). Six patients demonstrated SD lasting at least 6 months (median duration of SD was 7 months [range 1-13]). One patient with non-small cell lung cancer (NSCLC) treated Q3W with MK-2206 and docetaxel demonstrated a confirmed PR; this patient had received 2 prior lines of platinum-based chemotherapy and erlotinib. Figures 2C and 2D illustrate the overall best responses in evaluable patients in arms 2 and 3, respectively. Biomarker analysis was conducted on 68 patients, of whom 7 tested positive for mutations. Four patients carried a PIK3CA mutation (exon 20) and 3 carried a KRAS (exon 12) mutation. Patients harboring PIK3CA mutations demonstrated SD ranging from 1.7 to 5.8 months, whereas patients with $K R A S$ mutations had SD ranging from 1.4 to 3.0 months.

\section{Discussion}

Our study demonstrates that MK-2206 in combination with standard cytotoxic chemotherapies can be safely administered to patients with advanced solid tumors, at doses demonstrating antitumor activity. The combinations were tolerable, with the main DLTs being rash and febrile neutropenia. The most common AEs were fatigue, nausea, rash, diarrhea, and anorexia, with no apparent exacerbation of toxicities associated with standard agents. Of note, drug-related hyperglycemia-an expected effect of AKT inhibition-was evident in $<10 \%$ of patients, a rate similar to the single-agent phase 1 study [18].

At the 45-mg dose level in all schedules, mean $\mathrm{C}_{\text {trough }}$ for MK-2206 was >56.8 nM, corresponding with 70\% AKT inhibition in the single-agent study [18]. The MTD and recommended schedule of MK-2206 in combination with carboplatin AUC 6 and paclitaxel $200 \mathrm{mg} / \mathrm{m}^{2}$ were defined as $135 \mathrm{mg}$ Q3W. With docetaxel, the MTD of MK-2206 was not reached, but the MAD of MK-2206 was defined as $200 \mathrm{mg}$ Q3W with docetaxel $60 \mathrm{mg} / \mathrm{m}^{2}$. The dose escalation of this combination was not further investigated due to a high neutropenia rate when docetaxel was administered at $75 \mathrm{mg} / \mathrm{m}^{2}$ and the lack of clinical activity; this $60 \%$ rate of febrile neutropenia may be a reflection of the small patient numbers. However, it was felt that these 2 factors would likely limit the future use of this combination. The MK-2206 plus erlotinib combination reached the MAD of $135 \mathrm{mg}$ QW and $150 \mathrm{mg}$ daily, respectively. Based on emerging data from the monotherapy phase 1 study where MK-2206 MTD is limited to $200 \mathrm{mg}$ QW, as 


\section{A}
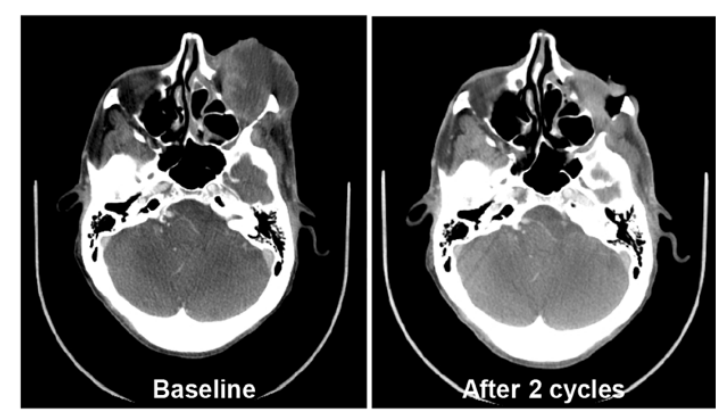

B

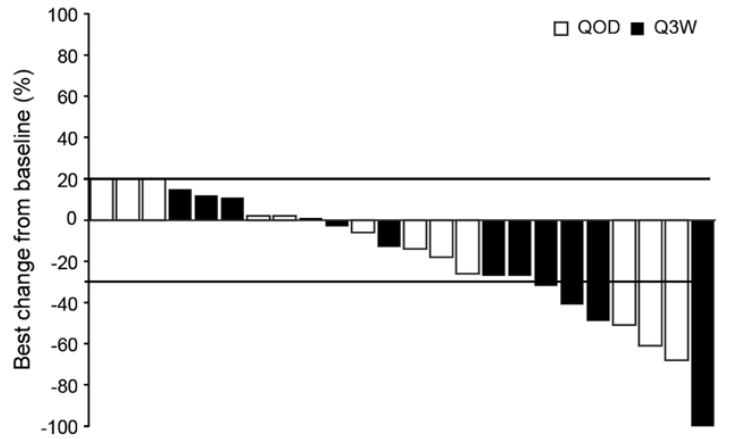

C

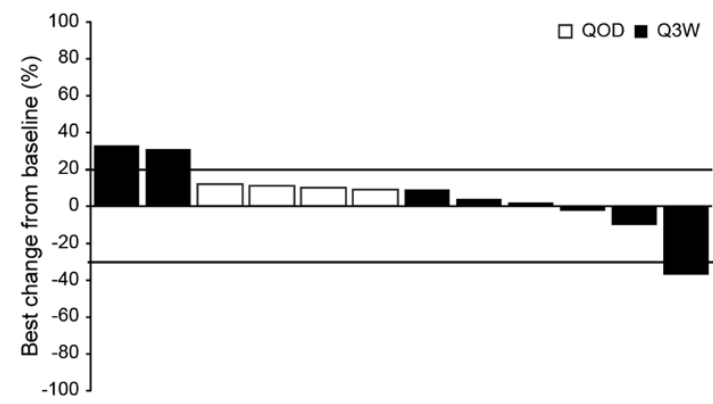

D

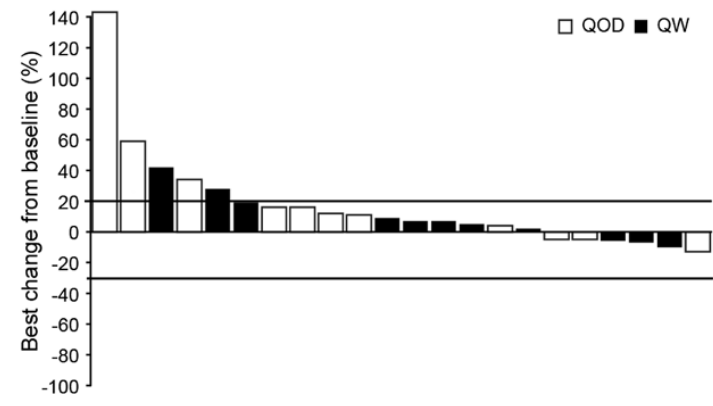

Figure 2 Best radiological response (RECIST) associated with MK-2206 combinations. CT scan slices demonstrating a CR in a male patient with SCC of the orbit (A). Waterfall plots of the best responses seen in all evaluable patients in arm 1, carboplatin and paclitaxel (B), arm 2, docetaxel (C), and arm 3, erlotinib (D). In arm 1, 6 patients treated in both schedules of MK-2206 with carboplatin and paclitaxel chemotherapy had PRs: with 4 of these being confirmed: melanoma ( $n=1,21$-month duration -8 months while on study and 13 months after study discontinuation), neuroendocrine prostate $(n=1$, 6-month duration), cervical ( $n=1,6$-month duration), and endometrial ( $n=1,4$-month duration); and 2 were unconfirmed: gastric $(n=1$, 2-month duration) and SCC of the head and neck ( $n=1,2$-month duration). In arm 2, a female patient with NSCLC who had progressed through pemetrexed-platinum and erlotinib achieved a PR with MK-2206 200 mg lasting 6 months. The patient withdrew from the study due to docetaxel-related toxicities, before documentation of progressive disease. No objective responses were observed in arm 3: the best response was SD lasting 7 and 6 months in a male patient with NSCLC and a patient with cervical cancer, respectively. Dashed lines indicate the threshold for PD ( $\geq 20 \%$ increase) and PR ( $\geq 30 \%$ decrease) based on the change in the sum of target lesions from baseline by Response Evaluation Criteria in Solid Tumors guidelines. $C T=$ computed tomography; $C R=$ complete response; $S C C=$ squamous cell carcinoma; $\mathrm{PR}=$ particle response; NSCLC = non-small cell lung cancer; $\mathrm{SD}=$ stable disease; $\mathrm{PD}$ = progressive disease; $\mathrm{QOD}=$ alternate days; $\mathrm{Q} 3 \mathrm{~W}=$ every 3 weeks; $\mathrm{QW}=$ week.

well as the overlapping skin toxicity profiles of these two agents, it was decided that the risk of further dose escalation outweighed the potential benefit and therefore the MAD is the recommended phase 2 dose (RP2D).

The anticancer activity of the combinations, particularly MK-2206/carboplatin and paclitaxel, was notable, with durable responses seen in some patients previously exposed to platinum and taxane compounds. There was no correlation between responses or prolonged SD with mutations activating the PI3K pathway, although 1 metastatic breast cancer patient harboring a PIK3CA mutation (exon 20), previously treated with 3 lines of chemotherapy and 1 line of hormonal therapy with progressive disease, demonstrated SD for 4 months. Phase 1 studies of MK-2206 with paclitaxel in breast cancer and with paclitaxel and trastuzumab in patients overexpressing human epidermal growth factor receptor-2 are underway.

Preclinical data in NSCLC cell lines suggest a strong rationale for the combination of MK-2206 and erlotinib $[19,26]$. In our study, most patients with NSCLC $(n=5)$ were treated on the less well-tolerated and possibly suboptimal QOD schedule. Using the QW schedule, only 1 patient with NSCLC, who achieved a best response of SD lasting 7 months, was included. The antitumor activity of this combination is likely to be best determined in selected patients with molecularly characterized tumors. The combination is currently being investigated in an open-label, phase 2 trial of patients with advanced NSCLC. A phase 1 study is also investigating the combination of MK-2206 with gefitinib in patients who 
progressed on prior treatment with an epidermal growth factor receptor (erlotinib or gefitinib) inhibitor. Previous results suggest that tumors with KRAS mutations are more effectively inhibited with a combination of an AKT and a MEK inhibitor [27,28]. These combinations are being further explored in the Biomarker Integrated Targeted Therapy Program (BATTLE-2), where recruitment into different arms is based on the molecular status of the patient's tumor [29].

Based on the early evidence of clinical activity, larger phase 2 randomized studies are underway in various tumor types to test whether the addition of MK-2206 to standard treatment enhances antitumor effects. One such study is assessing the combination with the anti-androgen bicalutamide, where patients with prostate cancer are randomized to receive bicalutamide with or without MK-2206. Dysregulation of the PI3K pathway is one of the most frequent mechanisms of resistance to conventional anti-androgen therapy [30], highlighting a need for effective agents that could inhibit cell signalling via this pathway. Another study is investigating the efficacy of the addition of MK-2206 to anastrazole or fulvestrant, and comparing these combinations to either agent alone in women with metastatic breast cancer.

In conclusion, our study shows that MK-2206, using a QOD, QW, or Q3W dosing schedule in combination with carboplatin and paclitaxel, docetaxel, or erlotinib, was well-tolerated at doses that inhibit AKT signaling. Phase 2 programs are underway to further investigate the combination of MK-2206 with carboplatin and paclitaxel or erlotinib, which along with other randomized phase 2 studies should provide a broad clinical profile of MK-2206 in combination with other standard cytotoxic or targeted treatment options.

\footnotetext{
Abbreviations

AEs: Adverse events; ATP: Adenosine triphosphate; BATTLE-2: Biomarker integrated targeted therapy program; CT: Computed tomography; DLT: Dose-limiting toxicities; MAD: Maximum administered dose; MTD: Maximum tolerated dose; mTOR: mammalian target of rapamycin; $\mathrm{NCl}$-CTCAE: National cancer institute common terminology criteria for adverse events; NSCLC: Non-small cell lung cancer; PD: Pharmacodynamics; PI3K: Phosphatidylinositide 3-kinase; PK: Pharmacokinetics; PO: Orally; QOD: Alternate day; QW: Weekly; Q3W: Once every 3 weeks;

RP2D: Recommended phase 2 dose; SD: Stable disease.
}

\section{Competing interests}

The following authors declare financial interest in the work presented in the submitted manuscript: LRM, DMS, LLS, AP, and KPP have received research funding from Merck \& Co., Inc. LY and ET are employees of and own stock in Merck. AMZ is an employee of Merck \& Co., Inc. AWT has acted as a consultant or advisor for AbbVie, Aragon, Arqule, Astellas, Astex (formerly Supergen), Bayer HealthCare, Bind Biosciences, BioMed Valley, Bristol-Myer Squibb, Celator, Curis, Cytomx, Dicerna, EMD Serono, Inc., Endo, Five Prime Therapeutics Inc., Genentech, Lilly, Merck \& Co., Inc., Mercus, Nanobiotx, Nektar, Neumedicines, Novartis, OncoMed, Pfizer, Pierre Fabre, Prism Pharma Co., Ltd, ProNai, Sanofi, Specialized Medical Services-Oncology BV, Sympogen, Theraclone, Vaccinex, and Zyngenia. JV-P, PAC, EC, AB, JSdB, and SM have no conflicts of interest to disclose.

\section{Authors' contributions}

LRM collected and assembled data and interpreted and analyzed the data, and participated in writing the manuscript. JV-P participated in writing of the manuscript. AMZ assisted with conception and design of the study, collected and assembled data, and conducted data analysis and interpretation; participated in writing the manuscript; and provided administrative support and provided patients or study materials. DMS conducted data analysis and interpretation and participated in writing the manuscript. PAC and EC collected or assembled data and participated in writing the manuscript. AB collected and assembled data and participated in writing the manuscript. ET interpreted and analyzed the data and participated in writing the manuscript. LLS collected and assembled the data, provided patients or study materials and participated in writing the manuscript. AP collected and assembled the data and participated in writing the manuscript. KPP collected and assembled the data, provided patients or study materials and participated in writing the manuscript. JdB assisted with conception and design of the study and collection and assembly of data and provided study material or patients. AWT assisted with conception and design of the study, collection and assembly of data, and did data analysis and interpretation; participated in writing of the manuscript; and provided study material or patients. SM assisted with conception and design of the study, did data analysis and interpretation, and participated in writing the manuscript. All authors approved the final version of the manuscript. All authors read and approved the final manuscript.

\section{Acknowledgments}

The authors would like to acknowledge Janusz Mezynski (subinvestigator), Jen Lewis (trial coordinator) and Bhavesh Anghan (clinical data manager), all employees at the Royal Marsden NHS Foundation Trust and The Institute of Cancer Research, for their support of and contribution to the clinical study and the development of the manuscript. Editorial assistance was provided by Integrus Scientific, a division of Medicus International New York (New York, NY). This assistance was funded by Merck \& Co., Inc. Martha Carroll Vollmer, MA, of Merck, provided editorial assistance. The authors are fully responsible for all content and editorial decisions and received no financial support or other compensation related to the development of the manuscript.

\section{Grant support}

The Drug Development Unit of the Royal Marsden NHS Foundation Trust and The Institute of Cancer Research (ICR) are supported in part by a program grant from Cancer Research UK (C309/A11566). Support was also provided by the Experimental Cancer Medicine Centre (ECMC Award C12540/A15573, to The Institute of Cancer Research) and the National Institute for Health Research Biomedical Research Centre (NIHR BRC; joint to the Royal Marsden and ICR).

\section{Financial support}

This study was supported by Merck \& Co., Inc. (Whitehouse Station, NJ). The Drug Development Unit of the Royal Marsden NHS Foundation Trust and The Institute of Cancer Research are supported in part by a program grant from Cancer Research UK. Support was also provided by the Experimental Cancer Medicine Centre (to The Institute of Cancer Research).

\section{Author details}

${ }^{1}$ Drug Development Unit, The Institute of Cancer Research/The Royal Marsden NHS Foundation Trust, Downs Road, Sutton, Surrey SM2 5PT, UK. ${ }^{2}$ Merck \& Co., Inc., One Merck Drive, Whitehouse Station, NJ 08889, USA. ${ }^{3} \mathrm{H}$. Lee Moffitt Cancer Center \& Research Institute, 12902 Magnolia Drive, Tampa, FL 33612, USA. ${ }^{4}$ Drug Development Programme, Princess Margaret Hospital, 610 University Avenue, 5-700, Toronto, ON M5G 2 M9, Canada. ${ }^{5}$ South Texas Accelerated Research Therapeutics (START), 4383 Medical Drive, San Antonio, TX 78229, USA. ${ }^{6}$ Division of Clinical Sciences, The Institute of Cancer Research, 15 Cotswold Road, Belmont, Sutton, Surrey SM2 5NG, UK. ${ }^{7}$ Department of Medicine, Centre Léon Bérard, 28 rue Laennec, 69008 Lyon, France.

Received: 26 September 2013 Accepted: 24 December 2013 Published: 3 January 2014

\section{References}

1. Carnero A: The PKB/AKT pathway in cancer. Curr Pharm Des 2010, 16:34-44. 
2. Liu LZ, Zhou XD, Qian G, Shi X, Fang J, Jiang BH: AKT1 amplification regulates cisplatin resistance in human lung cancer cells through the mammalian target of rapamycin/p70S6K1 pathway. Cancer Res 2007 67:6325-6332.

3. West KA, Castillo SS, Dennis PA: Activation of the PI3K/Akt pathway and chemotherapeutic resistance. Drug Resist Updat 2002, 5:234-248.

4. Engelman JA: Targeting PI3K signalling in cancer: opportunities, challenges and limitations. Nat Rev Cancer 2009, 9:550-562.

5. Courtney KD, Corcoran RB, Engelman JA: The PI3K pathway as drug target in human cancer. J Clin Oncol 2010, 28:1075-1083.

6. Yan L, Rosen N, Arteaga C: Targeted cancer therapies. Chin J Cancer 2011, 30:1-4.

7. Yap TA, Garrett MD, Walton MI, Raynaud F, De Bono JS, Workman P. Targeting the PI3K-AKT-mTOR pathway: progress, pitfalls, and promises Curr Opin Pharmacol 2008, 8:393-412.

8. Franke TF, Yang SI, Chan TO, Datta K, Kazlauskas A, Morrison DK, Kaplan DR, Tsichlis PN: The protein kinase encoded by the Akt proto-oncogene is a target of the PDGF-activated phosphatidylinositol 3-kinase. Cell 1995, 81:727-736

9. Scheid MP, Woodgett JR: PKB/AKT: functional insights from genetic models. Nat Rev Mol Cell Biol 2001, 2:760-768.

10. Testa JR, Tsichlis PN: AKT signaling in normal and malignant cells. Oncogene 2005, 24:7391-7393.

11. Irie HY, Pearline RV, Grueneberg D, Hsia M, Ravichandran P, Kothari N, Natesan S, Brugge JS: Distinct roles of Akt1 and Akt2 in regulating cell migration and epithelial-mesenchymal transition. J Cell Biol 2005, 171:1023-1034.

12. Winograd-Katz SE, Levitzki A: Cisplatin induces PKB/Akt activation and p38(MAPK) phosphorylation of the EGF receptor. Oncogene 2006, 25:7381-7390.

13. Brognard J, Clark AS, Ni Y, Dennis PA: Akt/protein kinase B is constitutively active in non-small cell lung cancer cells and promotes cellular survival and resistance to chemotherapy and radiation. Cancer Res 2001, 61:3986-3997.

14. Clark AS, West K, Streicher S, Dennis PA: Constitutive and inducible Akt activity promotes resistance to chemotherapy, trastuzumab, or tamoxifen in breast cancer cells. Mol Cancer Ther 2002, 1:707-717.

15. Okuzumi T, Fiedler D, Zhang C, Gray DC, Aizenstein B, Hoffman R, Shokat KM: Inhibitor hijacking of Akt activation. Nat Chem Biol 2009, 5:484-493.

16. Yan $L$ : A potent allosteric AKT inhibitor. AACR 2009. abstract DDT01-1.

17. Biondo A, Yap TA, Yan L, Patnaik A, Fearen I, Baird RD, Papadopoulos KP, Delgado LM, Taylor A, Lupinacci L, et al: Phase 1 clincial trial of an allosteric AKT inhibitor, MK-2206, using a once weekly (OW) dose regimen in patients with advanced solid tumors. J Clin Oncol 2011, 29:3037.

18. Yap TA, Yan L, Patnaik A, Fearen I, Olmos D, Papadopoulos K, Baird RD Delgado L, Taylor A, Lupinacci $L$, et al: First-in-man clinical trial of the oral pan-AKT inhibitor MK-2206 in patients with advanced solid tumors. J Clin Oncol 2011, 29:4688-4695.

19. Hirai H, Sootome H, Nakatsuru Y, Miyama K, Taguchi S, Tsujioka K, Ueno Y, Hatch H, Majumder PK, Pan BS, et al: MK-2206, an allosteric Akt inhibitor, enhances antitumor efficacy by standard chemotherapeutic agents or molecular targeted drugs in vitro and in vivo. Mol Cancer Ther 2010, 9:1956-1967.

20. Ji Y, Li Y, Nebiyou BB: Dose-finding in phase I clinical trials based on toxicity probability intervals. Clin Trials 2007, 4:235-244.

21. Perkins $G$, Yap TA, Pope $L$, et al: Multi-purpose utility of circulating plasma DNA testing in patients with advanced cancers. PLoS One 2012, 7(11):e47020

22. Therasse P, Arbuck SG, Eisenhauer EA, Wanders J, Kaplan RS, Rubinstein L, Verweij J, Van Glabbeke M, Van Oosterom AT, Christian MC, et al: New guidelines to evaluate the response to treatment in solid tumors. European Organization for Research and Treatment of Cancer, National Cancer Institute of the United States, National Cancer Institute of Canada. J Natl Cancer Inst 2000, 92:205-216.

23. Baker SD, Zhao M, Lee CK, Verweij J, Zabelina Y, Brahmer JR, Wolff AC, Sparreboom A, Carducci MA: Comparative pharmacokinetics of weekly and every-three-weeks docetaxel. Clin Cancer Res 2004, 10:1976-1983.

24. Ten Tije AJ, Verweij J, Carducci MA, Graveland W, Rogers T, Pronk T, Verbruggen MP, Dawkins F, Baker SD: Prospective evaluation of the pharmacokinetics and toxicity profile of docetaxel in the elderly. J Clin Oncol 2005, 23:1070-1077.
25. Van Zuylen L, Sparreboom A, Van der GA, van der Burg ME, Van BV, Bol CJ, Woestenborghs R, Palmer PA, Verweij J: The orally administered P-glycoprotein inhibitor R101933 does not alter the plasma pharmacokinetics of docetaxel. Clin Cancer Res 2000, 6:1365-1371.

26. Mack C, Farneth N, Mahaffey C, Lara P, Gandara DR: Impact of AKT inhibitor MK-2206 on erlotinib resistance in non-small cell lung cancer (NSCLC). J Clin Oncol 2011, 29:7573.

27. Engelman JA, Chen L, Tan X, Crosby K, Guimaraes AR, Upadhyay R, Maira M, McNamara K, Perera SA, Song Y, et al: Effective use of PI3K and MEK inhibitors to treat mutant Kras G12D and PIK3CA H1047R murine lung cancers. Nat Med 2008, 14:1351-1356.

28. Tolcher AW, Baird RD, Patnaik A, Moreno Garcia V, Papadopoulos KP, Garrett CR, Olmos D, Shannon KA, Zazulina V, Eubin EH, Smith IC, Ryan J, Smith PD, Taylor A, Learoyd M, Lupinacci L, Yan L, De Bono JS: A phase I dose-escalation study of oral MK-2206 (allosteric AKT inhibitor) with oral selumetinib (AZD6244; MEK inhibitor) in patients with advanced or metastatic solid tumors. J Clin Oncol 2011, 29:3004

29. Kim ES, Herbst RS, Wistuba II, Lee JJ, Blumenschein GR Jr, Tsao A, Stewart DJ, Hicks ME, Erasmus J Jr, Gupta S, et al: The BATTLE trial: personalizing therapy for lung cancer. Cancer Discov 2011, 1:44-53.

30. Sarker D, Reid AH, Yap TA, De Bono JS: Targeting the PI3K/AKT pathway for the treatment of prostate cancer. Clin Cancer Res 2009, 15:4799-4805.

doi:10.1186/1756-8722-7-1

Cite this article as: Molife et al:: Phase 1 trial of the oral AKT inhibitor MK-2206 plus carboplatin/paclitaxel, docetaxel, or erlotinib in patients with advanced solid tumors. Journal of Hematology \& Oncology 2014 7:1.

\section{Submit your next manuscript to BioMed Central and take full advantage of:}

- Convenient online submission

- Thorough peer review

- No space constraints or color figure charges

- Immediate publication on acceptance

- Inclusion in PubMed, CAS, Scopus and Google Scholar

- Research which is freely available for redistribution
C BioMed Central 